\title{
Evaluating the Safety and Efficacy of a Highly Viscous 33-mg/mL Hyaluronic Acid Volumizing Filler in the Treatment of Facial Wrinkles: An Open-Labeled, Clinical Trials
}

\author{
Elnaz Razavian ${ }^{1}$, Setareh Tehrani ${ }^{2 \bowtie}$
}

${ }^{1}$ Tehran Medical Sciences Branch, Islamic Azad University, Tehran, Iran

${ }^{2}$ Department of Dermatology, Tehran Medical Sciences Branch, Islamic Azad University, Tehran, Iran

\begin{abstract}
Background: The 33-mg/mL hyaluronic acid (HA) formulation is a highly concentrated, crosslinked, cohesive, smooth, and completely reversible volumizing filler approved by Conformité Européene. For the first time, we aimed to evaluate the long-term efficacy and safety of the 33$\mathrm{mg} / \mathrm{mL}$ HA filler for soft tissue augmentation in the treatment of facial wrinkles. Materials and Methods: After optimal wrinkle correction was achieved in the patients undergoing treatment by injecting the $33-\mathrm{mg} / \mathrm{mL} \mathrm{HA}$ filler at the injection site plus one touch-up at a 2-week interval, the safety and efficacy of the filler were assessed on the 5-point Facial Volume Loss Scale through the 1-year study period. Patients were evaluated daily for 14 days and after 6 and 12 months post-treatment. Results: A total of 86 subjects were treated. The mean wrinkle scores of the patients were 3.95+0.79 (range of 3-5) before treatment, 2.3+0.94 (range 1-5) six months after treatment, and $2.93+1.29$ (range of 1-5) one year after treatment. Clinically significant mean wrinkle correction $(\mathrm{P}=0.001)$ was still evident at $>12$ months of treatment through $33-\mathrm{mg} /$ $\mathrm{mL} H A$ formulation. A clinically significant correction at $>12$ months after treatment was maintained by $79 \%$ of patients. Nodule formation and swelling were more frequent when the 33$\mathrm{mg} / \mathrm{mL}$ HA filler was used compared with the use of less concentrated HA fillers. One patient developed angioedema-like swelling and induration last few months. Conclusion: The 33-mg/ mL HA filler can provide long-term correction lasting for one year or more. Adverse effects, especially swelling and nodule formation were more common in this filler compared with less concentrated HA fillers. The side effects were correlated with the volume of the injected filler. We recommend using this concentration with low volume or combining high volume with lower concentration. [GMJ.2019;8:e1148] DOI:10.31661/gmj.v8i0.1148
\end{abstract}

Keywords: Hyaluronic Acid; Wrinkles; Aging Face; Dermal Filler

\section{Introduction}

Gacial aging is caused by intrinsic and extrinsic factors such as smoking, genetics, muscle activity, and sun exposure [1-4]. Facial aging changes appear as a result of the loss of

\section{GMJ}

Copyright $\odot$ 2019, Galen Medical Journal. This is an open-access article distributed under the terms of the Creative Commons Attribution 4.0 International License (http://creativecommons.org/licenses/by/4.0/) Email:info@gmj.ir elastin, loss of bone mass, atrophy of soft tissue, as well as altered collagen production [5]. These changes are associated with skin laxity and volumetric loss. Multiple treatment options are available for these skin changes. One of them is treatment by dermal fillers. Dermal

\footnotetext{
Correspondence to:

Setareh Tehrani MD, Department of Dermatology,

Tehran Medical Science Branch, Islamic Azad

University, Tehran, Iran

Telephone Number: +982188788919

Email Address: s_tehrani@iautmu.ac.ir
} 
fillers help retrieve facial volume and reduce facial rhytides without any surgical approach. The Food and Drug Administration (FDA) approved more than 13 injectable fillers between 2000 and 2011. Showing a 1-year increase of $8.6 \%$, United States reported 995,000 soft-tissue filler procedures in 2013. A glycosaminoglycan disaccharide named hyaluronic acid (HA), with a half-life of 3 days or less is naturally found in the human body, especially in skin [6].HA fillers play an integral part in the correction of changes associated with aging [7]. They are categorized as resorbable (such as HA) and permanent or non-resorbable (such as silicone) [8]. Every patient showing signs of skin aging wants ideal fillers that are easily injectable, yield reproducible results, and have a long-lasting effect. HA forms a major part of the extracellular matrix of the dermis. An average human body of $60 \mathrm{~kg}$ contains about $12 \mathrm{~g}$ of HA. This HA provides a space for the movement of cells as well as diffuses hormones and nutrients. It also stimulates the production of collagen besides fibroblast proliferation and migration. It regulates cell-to-cell and cell-to-matrix interactions by stimulating the cell membrane receptor CD44, thereby leading to regulated cell proliferation and motility [9].The cross-linking of HA with low molecular weight results in significantly increased viscosity [10]. The cross-linking agent 1,4-butanediol diglycidyl ether (BDDE) is used to cross-link the monophasic HA dermal fillers with the cross-linking grade between $1 \%$ and $20 \%$. The concentration of the HA filler is between 13.5 and $25 \mathrm{mg} / \mathrm{mL}$ (such as Juvéderm and Teosyal). Biphasic HA formulation consists of HA particles in suspension with a non cross-linked HA-diluted solution. The commonly used cross-linking agents are divinyl sulfone (DVS), diepoxy octane, and BDDE. The concentration of the HA fillers such as Matridur, Restylane, Perlane, Sub Q, and Puragen is between 20 and $25 \mathrm{mg} / \mathrm{m}$ [11].The product we used in this study was Variofil, a smooth, highly cohesive, viscous HA filler with the concentration of $33 \mathrm{mg} / \mathrm{mL}$. It is prepared from a non cross-linked HA by cross-linking it with DVS. Its cross-linking grade is $70 \%$ due to an extended cross-linking process [11]. This filler is produced by a German company, ADODERM GmbH, and approved by Conformité Européene (CE). It has been used mainly for body contour. We designed this study to evaluate the long-term effectiveness and safety of $33-\mathrm{mg} / \mathrm{mL}$ HA for facial wrinkle treatment. This study aimed to determine the use of highly concentrated HA fillers for the treatment of facial volume loss, having long-term sustainability with less frequency of injection and less cost for the patients, and also to evaluate their adverse effects because of high concentration.

\section{Materials and Methods}

\section{Participants}

This open-label, the non-randomized clinical study was performed on 96 patients aged 4060 years who attended our dermatology clinic during 2016-2017 at Tehran. Patients with facial volume loss scores of 3 to 5 based on the 5-point Facial Volume Loss Scale were included in this study. None had any exclusion criteria which include a history of receiving any treatment (include permanent, semi-permanent filler, implant) within the past 12 months, active infection near the site of injection, known allergy or hypersensitivity to HA, tendency to develop hypertrophic scars, autoimmune disease, active skin disease, intake vitamin $\mathrm{E}$ and aspirin two weeks before injection, pregnancy, and lactation. Figure-1 shows the flowchart of study. All 96 patients received the allocated intervention, and 86 participants completed all study procedures and follow-up. No participants were excluded from analyses.

\section{Trial Design}

At the day of administering the injection, the facial volume loss scores of the patients on the 5-point Facial Volume Loss Scale were determined as follows: $0=$ no wrinkle, $1=$ just perceptible wrinkles, $2=$ shallow wrinkles, $3=$ moderately deep wrinkles, $4=$ deep wrinkles with well-defined edges, and 5=very deep wrinkles with the redundant fold (Figure-2) [12]. The patient's age, sex, injection site, and volume per site were recorded. We injected a $33-\mathrm{mg} / \mathrm{mL}$ cohesive filler with either a cannula or needle subcuticularly. Topical anesthesia (include 23\% lidocaine and 3.5\% tetracaine $\mathrm{HCl}$ ) was used for most of the patients. The 


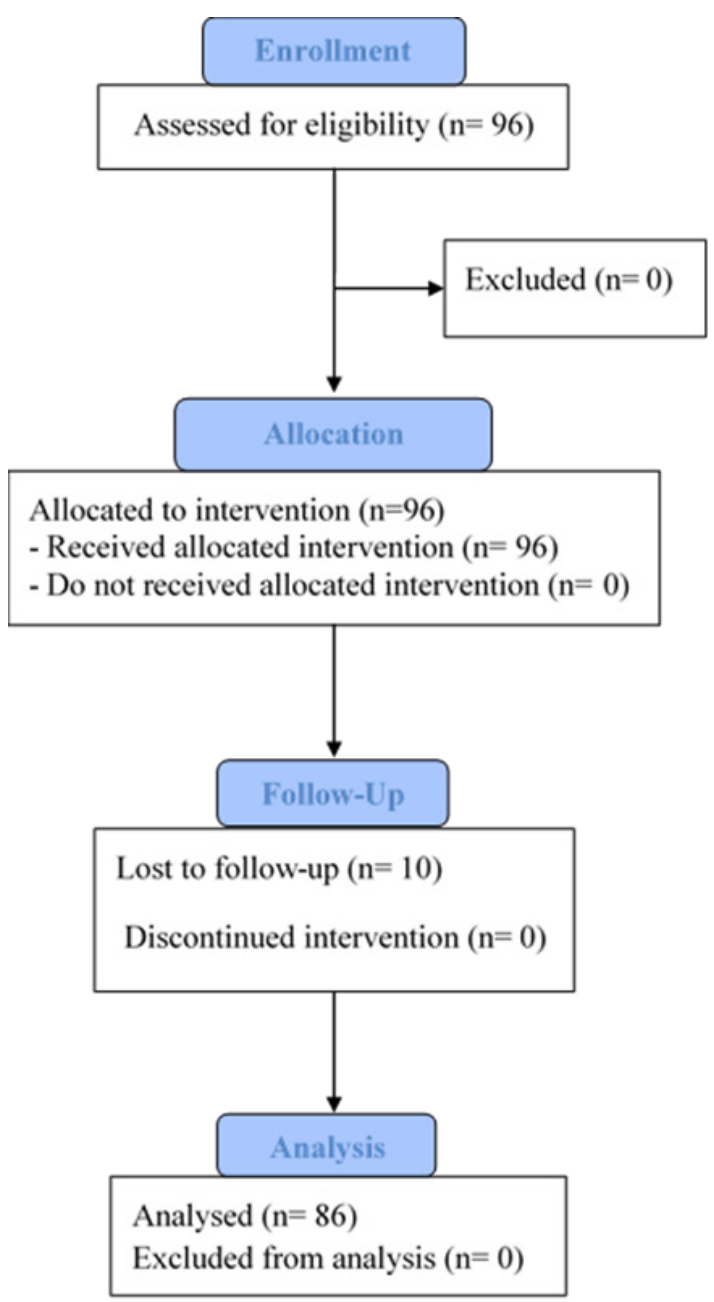

Figure 1. Flowchart of study

injection score after treatment was 0 for all the patients. One touch-up at a 2-week interval was performed for having an optimal correction. If there was any visible line or wrinkle mentioned, we injected more filler on a touchup day. The patients were evaluated daily for 14 days and after 6 and 12 months to determine the safety and longevity of the filler. The facial volume loss scores were recorded on each visit. Photographs were taken pre- and post-treatment at both visits. Site, severity, and duration of any adverse events following intervention were recorded and categorized into acute, intermediate, and long-term side effects. Percentage, mean, and ranges were used to report descriptive analysis.

\section{Ethical Issue}

The patients were informed about the objectives of the research, as well as the pos- sible complications before the beginning of the treatment. Written consent was obtained from each participant after getting mentioned descriptions before starting the process. The Ethical Committee of Tehran Medical Sciences Branch, Islamic Azad University has approved this study (IR.IAU. TMU.REC.1396.121), and it also registered in the Iranian Registry of Clinical Trials (RCT code: IRCT20180228038905N1).

\section{Statistical Analysis}

All data were analyzed by using the IBM SPSS Statistics for Windows, version 22 (IBM Corp., Armonk, N.Y., USA). via paired sample t-test and analysis of variance (ANOVA). The statistical significance level was set at $\mathrm{P} \leq 0.05$.

\section{Results}

In the present study, 71 females and 15 males were complete follow-up and included in the final analysis. The mean age of patients was $53 \pm 6.08$. Thirteen patients (15\%) were deemed to require touch-up treatment, with a mean volume of $0.51 \pm 1.09 \mathrm{~mL}$. The most frequent injected site was the nasolabial fold (NLF) area; it comprised $60 \%$ of the total injection sites. The mean injection volume for this site was $1.05 \pm 0.81 \mathrm{~mL}$ per site. The next most commonly injected site ( $21 \%$ of procedures) was the marionette line with a mean injection volume of $0.81 \pm 0.21 \mathrm{~mL}$. The malar area included $15 \%$ of the total injection sites, and the mean injection volume for the wrinkle correction of this area was $0.7 \pm 0.38 \mathrm{~mL}$. The remained area accounted $4 \%$ on the injected site with the mean volume of $0.8 \mathrm{ml} \pm 0.1$. The most common scoring grade before treatment was four ( $70 \%$ of patients) with a mean score of $3.95 \pm 0.79$ (Table-1). Six months after treatment, the most common scoring grade was two ( $47 \%$ of patients) with a mean score of $2.3 \pm 0.94$ and one year after treatment, it was three $(42 \%$ of cases) with a mean score of $2.93 \pm 1.29$. Clinically significant mean wrinkles correction (at least 1-point improvement) was evident six months and one year after injection of $33 \mathrm{mg} / \mathrm{mL}$ HA. A total of 68 patients $(79 \%)$ maintained the correction for one year (Figure-3). There was no significant 


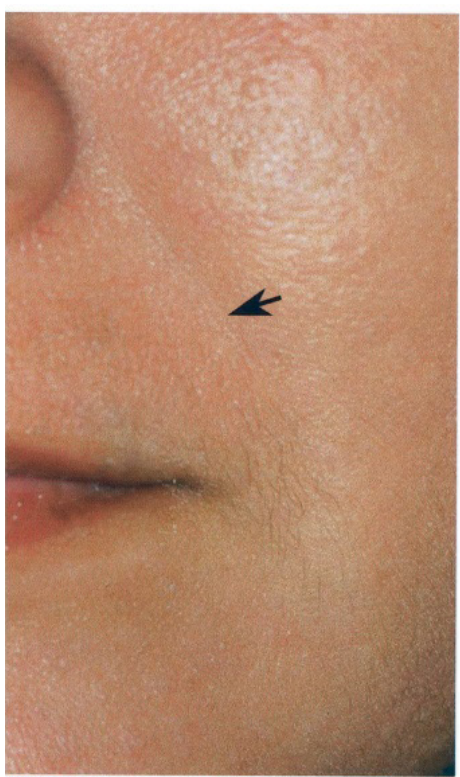

0

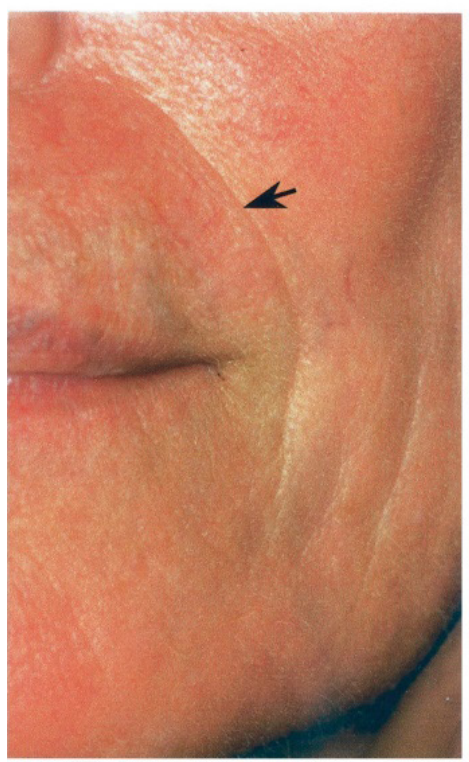

3

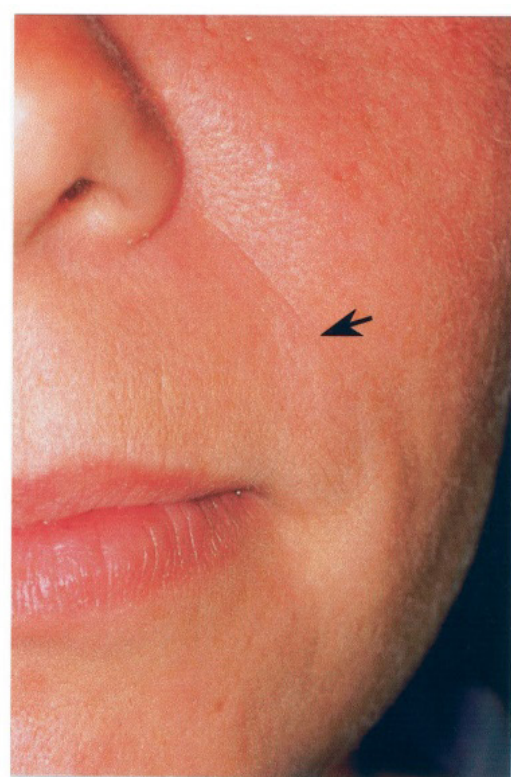

1

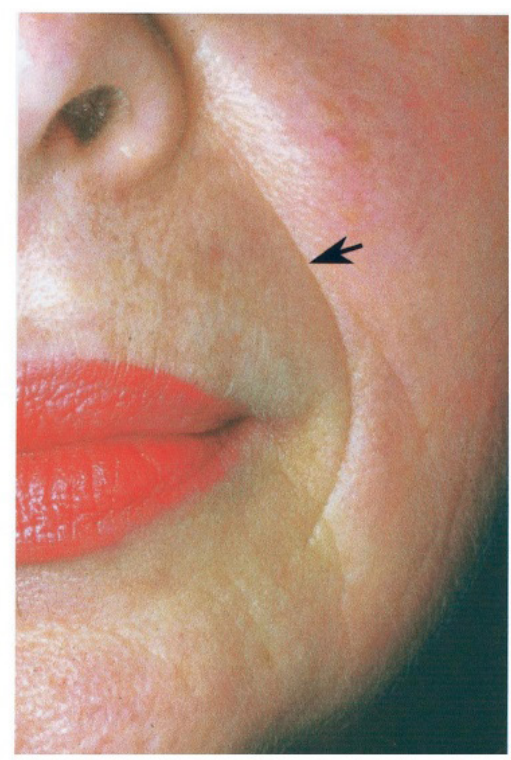

4
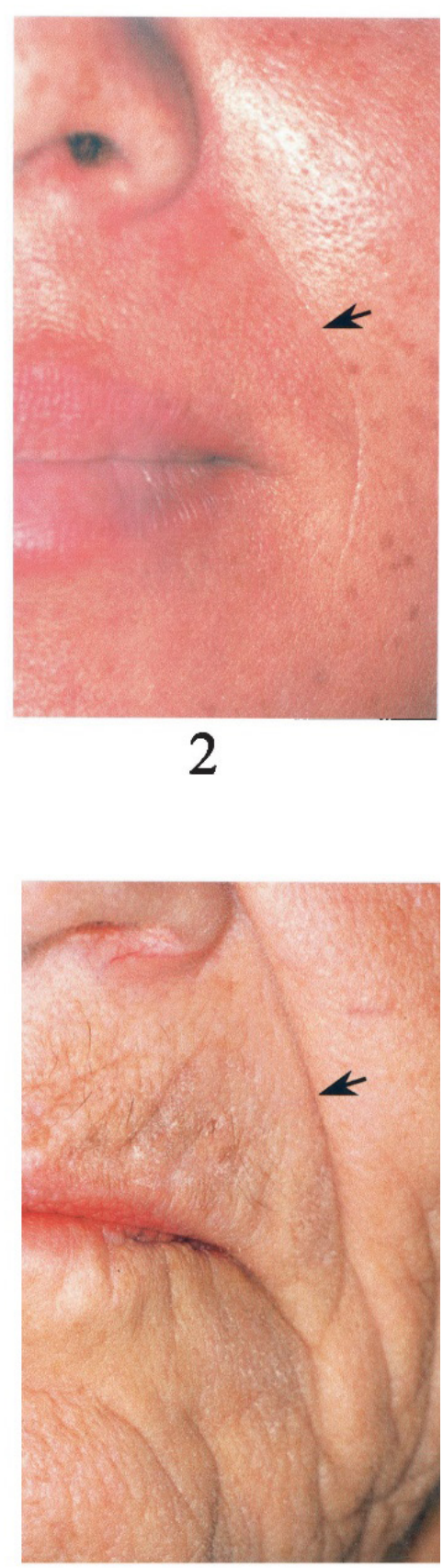

5

Figure 2. Pattern to determine the score of facial wrinkles [12]

correlation between the age and sex of the patients and the longevity of the filler $(\mathrm{P}>0.05)$. However, a significant relationship was found between the volume of the filler injected and its longevity $(\mathrm{P}=0.01)$. The more the volume of injection, the more the longevity. Also, there was a significant correlation between the site of injection and longevity $(\mathrm{P}=0.001)$. The least longevity was mentioned in NLF, whereas the most in marionette lines. As shown in
Table-2, $44.18 \%$ of the patients experienced no adverse effects. The mean duration of the reaction was 4.8 days. The most frequent side effects were swelling at the site of injection (20 patients), followed by nodular lesions and indurations in 12 cases at 16 sites. In most of the patients, the nodules were resolved with the help of pressure, facial massage and intense pulsed light treatment after several weeks. In the remainder, any such issue was 
Table 1. Volume Loss Ratings Based on the Wrinkle Classification Changes

\begin{tabular}{|c|c|c|c|c|c|c|c|c|}
\hline & \multicolumn{6}{|c|}{ Wrinkles score } & \multirow{3}{*}{ Mean \pm SD } & \multirow{3}{*}{ Range } \\
\hline & \multicolumn{6}{|c|}{$(\%)$} & & \\
\hline & $\mathbf{0}$ & 1 & 2 & 3 & 4 & 5 & & \\
\hline Before injection & 0 & 0 & $9 \%$ & $10 \%$ & $70 \%$ & $11 \%$ & $3.95 \pm 0.79$ & $3-5$ \\
\hline 6 months & 0 & $33 \%$ & $47 \%$ & $18 \%$ & $2 \%$ & 0 & $2.3 \pm 0.94^{\mathrm{a}}$ & $1-5$ \\
\hline 12 months & 0 & $2 \%$ & $30 \%$ & $42 \%$ & $21 \%$ & $5 \%$ & $2.93 \pm 1.29^{b}$ & $1-5$ \\
\hline
\end{tabular}

${ }^{\mathrm{a}} \mathrm{P}<0.01,{ }^{\mathrm{b}} \mathrm{P}<0.05$ vs. baseline

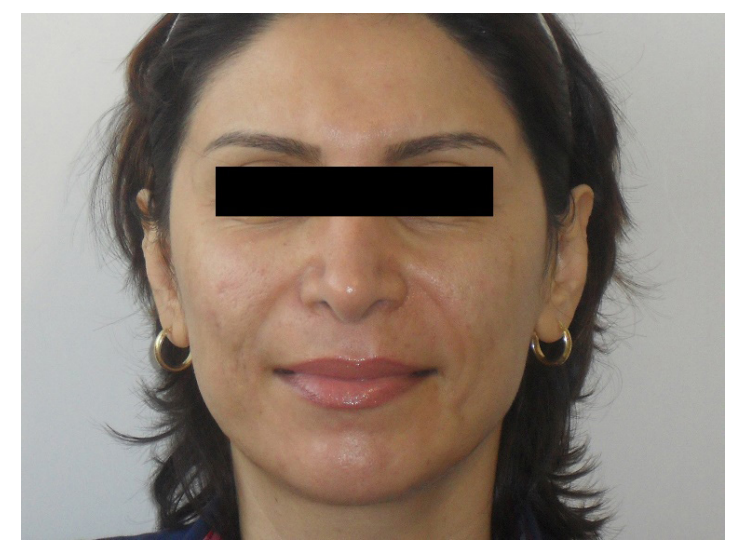

A

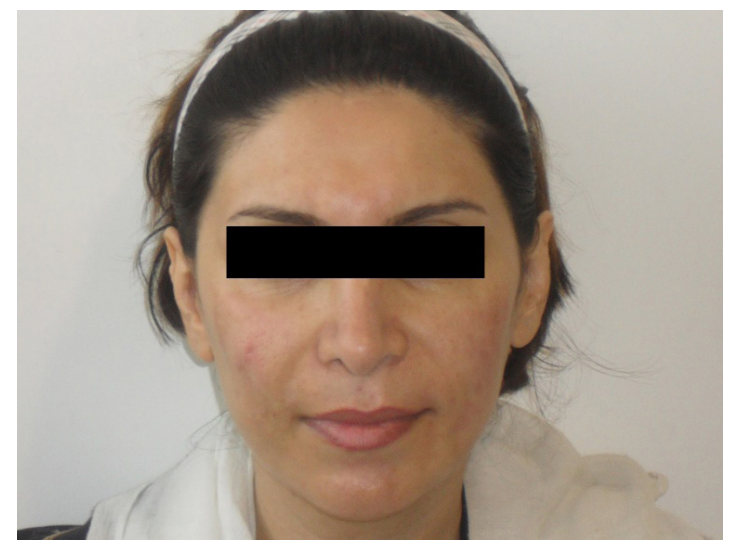

B

Figure 3. Injection of 1.5-mg/mL filler in the NLF. (A) Before injection and (B) after 12 months

Table 2. Adverse Effects in Studied Patients

\begin{tabular}{ccc}
\hline Adverse effects & N & \% \\
\hline Swelling & 20 & 23.25 \\
Nodules and/or indurations & 16 & 18.6 \\
Bruising & 5 & 5.81 \\
Bruising and Swelling & 3 & 3.5 \\
Persistent Nodules (>1year) & 3 & 3.5 \\
Angioedema swelling & 1 & 1.16 \\
None & 38 & 44.18 \\
\hline
\end{tabular}


fully resolved several months after injection, maximum six months. One patient developed angioedema-like swelling in the face four days after injection, which further increased after ten days of injection (Figure-4). The patient was treated with a systemic steroid dexamethasone (intramuscular) and prednisolone $40 \mathrm{mg} / \mathrm{d}$ for 20 days and tapered within weeks with the help of cetirizine and antibiotics (cephalexin and tetracycline). The edema resolved completely 25 days after injection.

\section{Discussion}

Correction of facial wrinkles is one of the most important cosmetic procedures. To the best of our knowledge, this is the first study to evaluate the use of a highly viscous $33-\mathrm{mg} /$ $\mathrm{mL}$ HA volumizing filler for treating facial wrinkles. This trial was designed to determine the efficacy and safety of this filler in patients with facial volume loss. Treatment of patients with facial aging by using a $33-\mathrm{mg} / \mathrm{mL}$ HA filler resulted in a statistically significant improvement, lasting beyond 1 year; however, it was not permanent. Highly concentrated cross-linked HA fillers that are the safest and approved by FDA and CE may last for more than six months. The use of HA fillers such as Juvéderm Ultra and Ultra Plus $(24 \mathrm{mg} / \mathrm{mL})$ resulted in clinically significant mean wrinkle correction at $>9$ months [13]. Restylane and Perlane $(20 \mathrm{mg} / \mathrm{mL})$ resulted in the maintenance of wrinkle correction by investigators. Elevess $(28 \mathrm{mg} / \mathrm{mL})$ was used in $60 \%$ to $80 \%$ of patients with mild and moderate folds and $40 \%$ to $60 \%$ of patients with deeper folds [1416]. The assessments suggest that six months after the last treatment, Juvéderm Ultra, and Ultra Plus made a clinically significant improvement in the mean wrinkle severity (1.3 and 1.5 points, respectively) [17], whereas Restylane (0.9 points) or Elevees did not ( 0.8 points) $[15,17]$. All cosmetic procedures might result in undesirable adverse effects. Therefore, it is imperative to review all known potential side effects with the patient before any procedures [18]. Some adverse reactions are localized and temporary, including pain, induration, swelling, nourishing, itching, er-

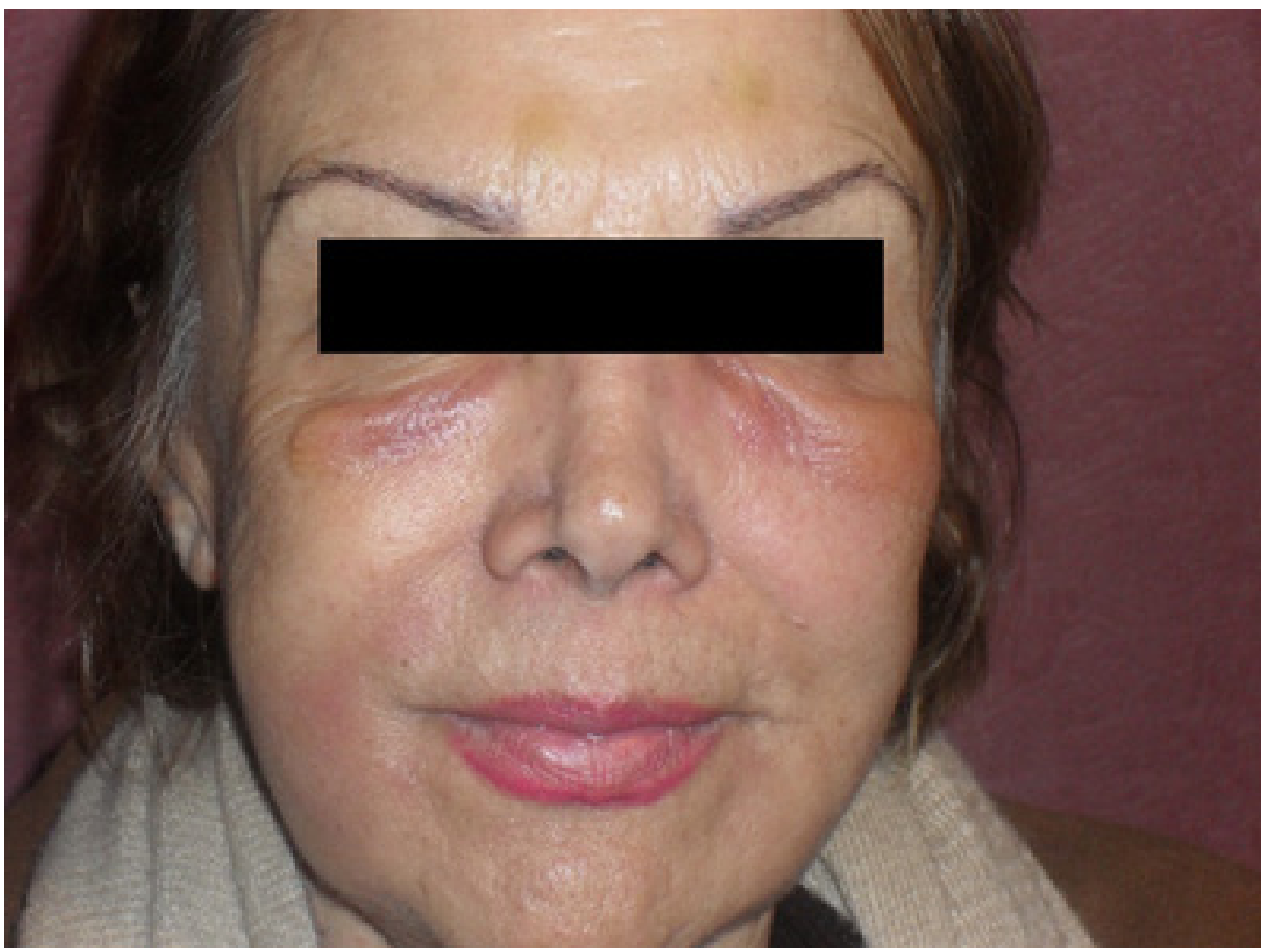

Figure 4. Angioedema-like swelling with the injection of 33-mg/mL filler for the augmentation of malar, NLF, and marionette lines 
ythema, acne form eruptions, transient lumpiness, and sterile abscess $[15,18,19]$. Few adverse reactions were reported before 2010 , and most of them were considered to be related to the treatment procedure. However, recent studies have reported hypersensitivity reactions to HA and another gel component [8, 20-23]. Previous studies have mentioned that these adverse effects, especially allergic ones, may be attributable to the protein component of HA associated with the impurities of the fermentation process $[24,25]$. Some adverse effects such as fever, arthritis, skin lesions, arthralgia, angioedema, skin induration, edema, nodules with or without fistulation, and pus discharge are delayed immune-mediated reactions (DIMR), which may be intermediate (1-12 months after injection) or delayed (12 months or more after injection) [19]. Studies by physicians reported different rates of injection-related reactions when using Restylane, Perlane, or Juvéderm from $13 \%$ to $34 \%$ or even to $80 \%[14,26]$. The overall incidence of DIMR is believed to be low. A review of 709 patients [27] treated with Hyaloform or Restylane demonstrated an incidence of DIMR of less than $0.5 \%$. Another retrospective study of 4,320 patients treated with Restylane reported an approximately $0.6 \%$ incidence of DIMR [28]. Only one case of angioedema-like swelling of the lip was recorded [29], although previous studies have reported this as a very common phenomenon following the injection of Restylane into lips [30]. Although there is no definite treatment modality for the correction of HA filler complications, we can manage them with various available treatment modalities (such as hyaluronidase injection) to minimize patient's morbidity [31]. In this study, adverse effects including swelling, bruising, nodules, and indurations were more common and frequent when compared with administration of less concentrated HA fillers (24\% of injected sites). Most of the nodular lesions were resolved with pressure and facial massage for several weeks after injection, but six lesions including 3\% of injected sides persisted several months (intermediate reaction), and three lesions, including 1.7 of sites persisted even 12 months after injection (delayed reaction).

\section{Conclusion}

Our study shows that the $33-\mathrm{mg} / \mathrm{mL}$ HA filler could correct facial wrinkles lasting for one year or more with less frequent injection and less cost. Adverse effects, especially swelling and nodule formation were more common compared with the use of less concentrated HA fillers. However, most of them were transient and correlated with the volume of the injected filler. We recommend using this filler with the combination of high concentration and low volume or high volume with lower concentrations.

\section{Acknowledgment}

We would like to thank the Islamic Azad University Tehran Medical Branch and ADODERM GmbH.

\section{Conflict of Interest}

None declared.

\section{References}

1. Smith L, Cockerham K. Hyaluronic acid dermal fillers: can adjunctive lidocaine improve patient satisfaction without decreasing efficacy or duration?. Patient Prefer Adherence. 2011;5:133-9

2. Levy PM, Boulle KD, Raspaldo H. A splitface comparison of a new hyaluronic acid facial filler containing pre-incorporated lidocaine versus a standard hyaluronic acid facial filler in the treatment of nasolabial folds. J Cosmet Laser Ther. 2009;11(3):169-
73.

3. Puizina-Ivic' N . Skin aging. Acta Dermatovenerol Alp Pannonica Adriat .2008;17(2):47-54.

4. Choi WJ, Han SW, Kim JE, Kim HW, Kim MB, Kang H. The efficacy and safety of lidocaine-containing hyaluronic acid dermal filler for treatment of nasolabial folds: a multicenter, randomized clinical study. Aesthetic Plast Surg. 2015;39(6):953-62.

5. Flament F, Bazin R, Laquieze S, Rubert V, 
Simonpietri E, Piot B. Effect of the sun on visible clinical signs of aging in Caucasian skin. Clin Cosmet Investig Dermatol. 2013;6:221-32.

6. Ho D, Jagdeo J. Biological properties of a new volumizing hyaluronic acid filler: a systematic review. J Drugs Dermatol. 2015;14(1):50-4.

7. Edwards PC, Fantasia JE. Review of longterm adverse effects associated with the use of chemically-modified animal and nonanimal source hyaluronic acid dermal fillers. Clin Interv Aging. 2007;2(4):509-19.

8. Requena L, Requena C, Christensen L, Zimmermann US, Kutzner H, Cerroni L. Adverse reactions to injectable soft tissue fillers. J Am Acad Dermatol. 2011;64(1):134.

9. Matarasso SL, Herwick R. Hypersensitivity reaction to nonanimal stabilized hyaluronic acid. J Am Acad Dermatol. 2006;55(1):12831.

10. Tezel A, Fredrickson GH. The science of hyaluronic acid dermal fillers. J Cosmet Laser Ther. 2008;10(1):35-42.

11. Micheels P. Human Anti-Hyaluronic Acid Antibodies: Is it Possible? Dermatol Surg. 2001;27(2):185-91.

12. Lamperle G, Holmes RE, Cohen SR, Lamperle SM. A classification of facial wrinkles. Plast Reconstr Surg. 2001;108(6):1735-50.

13. Pinsky MA, Thomas JA, Murphy DK, Walker PS, Group JvZNFS. Juvéderm injectable gel: a multicenter, double-blind, randomized study of safety and effectiveness. Aesthet Surg J. 2008;28(1):17-23.

14. Brandt FS, Cazzaniga A. Hyaluronic acid fillers: Restylane and Perlane. Facial Plast Surg Clin North Am. 2007;15(1):63-76.

15. Arsiwala SZ. Safety and persistence of non-animal stabilized hyaluronic acid fillers for nasolabial folds correction in 30 Indian patients. J Cutan Aesthet Surg. 2010;3(3):156-61.

16. Elevess [package insert] Woburn MA: Anika Therapeutics Inc, 2007.

17. Baumann LS, Shamban AT, Lupo MP, Monheit GD, Thomas JA, Murphy DK et al. Comparison of smooth-gel hyaluronic acid dermal fillers with cross-linked bovine collagen: A multicenter, double-masked, randomized, within-subject study. Dermatol Surg. 2007;33(s2):128-35.

18. Brandt FS, Cazzaniga A. Hyaluronic acid gel fillers in the management of facial aging.
Clin Interv Aging. 2008;3(1):153-9.

19. Alijotas-Reig J, Garcia-Gimenez V. Delayed immune-mediated adverse effects related to hyaluronic acid and acrylic hydrogel dermal fillers: clinical findings, long-term followup and review of the literature. J Eur Acad Dermatol Venereol. 2008;22(2):150-61.

20. Hanke CW. Evolution of filler materials in dermatology. J Am Acad Dermatol. 2013;68(5):858-9.

21. Luebberding S, Alexiades-Armenakas M. Safety of dermal fillers. J Drugs Dermatol. 2012;11(9):1053-8.

22. Gilbert E, Hui A, Waldorf H. The basic science of dermal fillers: past and present Part I: background and mechanisms of action. J Drugs dermatol. 2012;11(9):1059-68.

23. Piacquadio D, Jarcho M, Goltz R. Evaluation of hylan $\mathrm{b}$ gel as a soft-tissue augmentation implant material. J Am Acad Dermatol. 1997;36(4):544-9.

24. Prigent-Combaret C, Vidal O, Dorel C, Lejeune P. Abiotic surface sensing and biofilm-dependent regulation of gene expression in Escherichia coli. J Bacteriol. 1999;181(19):5993-6002.

25. Sclafani AP, Fagien S. Treatment of injectable soft tissue filler complications. Dermatol Surg. 2009;35(s2):1672-80.

26. Hoffmann K. Volumizing effects of a smooth, highly cohesive, viscous 20-mg/ $\mathrm{mL}$ hyaluronic acid volumizing filler: prospective European study. BMC Dermatol. 2009;9(1):9.

27. Lowe NJ, Maxwell CA, Lowe P, Duickb MG, Shah K. Hyaluronic acid skin fillers: adverse reactions and skin testing. J Am Acad Dermatol. 2001;45(6):930-3.

28. Andre P. Evaluation of the safety of a nonanimal stabilized hyaluronic acid (NASHAQ-Medical, Sweden) in European countries: a retrospective study from 1997 to 2001. J Eur Acad Dermatol Venereol. 2004;18(4):422-5.

29. Leonhardt JM, Lawrence N, Narins RS. Angioedema acute hypersensitivity reaction to injectable hyaluronic acid. Dermatol Surg. 2005;31(5):577-9.

30. Klein AW. Letter to the editor: re: hypersensitivity reactions to injectable hyaluronic acid: reality or fantasy?. Dermatol Surg. 2005;31(12):1745.

31. Park T-H, Seo S-W, Kim J-K, Chang C-H. Clinical experience with hyaluronic acidfiller complications. J Plast Reconstr Aesthet Surg. 2011;64(7):892-6. 